\title{
Estimating the day of highly pathogenic avian influenza (H7N7) virus introduction into a poultry flock based on mortality data
}

\author{
Marian E.H. Bos ${ }^{\mathrm{a} *}$, Michiel VAN Boven ${ }^{\mathrm{a}, \mathrm{b}}$, Mirjam NIELEN $^{\mathrm{a}}$, \\ Annemarie Bouma ${ }^{\mathrm{a}}$, Armin R.W. ELBERS ${ }^{\mathrm{c}}$, Gonnie NODELIJK ${ }^{\mathrm{b}}$, \\ Guus $\mathrm{KOCH}^{\mathrm{c}}$, Arjan STEGEMAN ${ }^{\mathrm{a}}$, Mart C.M. DE JONG ${ }^{\mathrm{d}}$ \\ ${ }^{a}$ Department of Farm Animal Health, Faculty of Veterinary Medicine, Utrecht University, \\ Utrecht, The Netherlands \\ ${ }^{\mathrm{b}}$ Division of Infectious Diseases, Animal Sciences Group, Wageningen University and Research Centre, \\ Lelystad, The Netherlands \\ ${ }^{c}$ Department of Virology, Central Institute for Animal Disease Control, Wageningen University \\ and Research Centre, Lelystad, The Netherlands \\ ${ }^{\mathrm{d}}$ Quantitative Veterinary Epidemiology Group, Department of Animal Sciences, \\ Wageningen University, Wageningen, The Netherlands
}

(Received 27 July 2006; accepted 19 December 2006)

\begin{abstract}
Despite continuing research efforts, knowledge of the transmission of the highly pathogenic avian influenza (HPAI) virus still has considerable gaps, which complicates epidemic control. The goal of this research was to develop a model to back-calculate the day HPAI virus is introduced into a flock, based on within-flock mortality data. The back-calculation method was based on a stochastic SEIR (susceptible (S) - latently infected (E) - infectious (I) - removed (= dead; R)) epidemic model. The latent and infectious period were assumed to be gamma distributed. Parameter values were based on experimental H7N7 within-flock transmission data. The model was used to estimate the day of virus introduction based on a defined within-flock mortality threshold (detection rule for determining AI). Our results indicate that approximately two weeks can elapse before a noticeable increase in mortality is observed after a single introduction into a flock. For example, it takes twelve (minimum 11 - maximum 15) days before AI is detected if the detection rule is fifty dead chickens on two consecutive days in a 10000 chicken flock (current Dutch monitoring rule for notification). The results were robust for flock size and detection rule, but sensitive to the length of the latent and infectious periods. Furthermore, assuming multiple introductions on one day will result in a shorter estimated period between infection and detection. The implications of the model outcomes for detecting and tracing outbreaks of H7N7 HPAI virus are discussed.
\end{abstract}

back-calculation / SEIR model / within-flock mortality / highly pathogenic avian influenza / H7N7

\section{INTRODUCTION}

Worldwide, the highly pathogenic avian influenza (HPAI) virus is causing societal

\footnotetext{
*Corresponding author: m.e.h.bos@ vet.uu.nl
}

and economical damage. In recent years, outbreaks have occurred in e.g. Hong Kong (1997) [17], Italy (1997, 1999) [4, 5], Canada (2004) [3] and regular outbreaks have occurred in Southeast Asia since 
2003 [18]. In 2003, HPAI virus subtype H7N7 caused an epidemic in The Netherlands [10,20]. Within two months 255 flocks were diagnosed as infected, and by the end of the epidemic around 30 million animals had been killed and destroyed, either pre-emptively or because they were from infected farms.

An important control measure during epidemics is forward tracing of the contacts of an infected farm in order to respond quickly to secondary infections [9]. For optimized tracing, knowing when a virus has been introduced into the infected flock or herd is essential, since it enables focusing on contacts between the time of virus introduction and culling.

However, this requires both identifying the contact that infected the flock (backward tracing), which is often unknown, and how HPAI is transmitted in a real poultry flock. To our knowledge, within-flock transmission has only been studied under experimental conditions, resulting in an indication of bird-to-bird transmission parameter values for the HPAI virus strain used in these experiments ${ }^{1}[21,22]$. However, there is a considerable gap between transmission experiments with a few animals and the field conditions of farms containing tens of thousands of animals.

In this paper, modeling was used to extrapolate the results from transmission experiments to field situations. The model shown in this paper constitutes the basis for a back-calculation method to estimate the day of virus introduction into a poultry flock based on within-flock mortality data, which is information easily obtained from poultry keepers. The model was applied on

\footnotetext{
${ }^{1}$ Van Boven M., Van der Goot J.A., Katsma E., Koch G., De Jong M.C.M., Transmissie van hoogpathogeen aviair influenzavirus in gevaccineerde en ongevaccineerde goudfazanten en roodschoudertalingen, Animal Sciences Group, Wageningen University and Research Centre, 2005 .
}

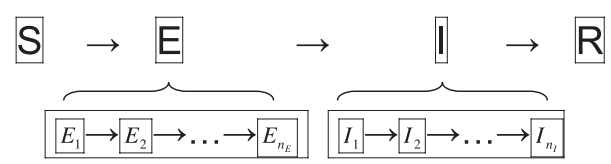

Figure 1. Graphical representation of the stages and classes in the model.

within-flock mortality data collected on infected farms during the Dutch AI H7N7 epidemic in 2003, and the implications are discussed.

\section{MATERIALS AND METHODS}

\subsection{Model}

We programmed a stochastic SEIR type epidemic simulation model, in which birds were either susceptible (S), infected but not yet infectious (= latently infectious) (E), infected and infectious (I) or removed (dead) (R) as the basis for the analyses. The latent and infectious periods were assumed to be gamma distributed with an integer-valued shape parameter to enable efficient simulations, using the "method of stages" $[6,12,13]$. In our model, susceptible birds that are infected have to pass through $n_{E}$ latent stages before becoming infectious (see Fig. 1 for a graphical representation of the stages and classes in the model). The per capita rate at which a bird leaves each latent stage is given by $n_{E} \gamma$ (with $\gamma$ denoting the rate at which a latent bird becomes infectious), so that the amount of time spent in the latent period is gamma distributed with mean $\frac{1}{\gamma}$ and variance $\frac{1}{n_{E} \gamma^{2}}$. After the last latent stage, birds go through $n_{I}$ infectious stages before dying, with per capita rate $n_{I} \mu$ per infectious stage (with $\mu$ denoting the rate at which an infectious bird dies). This implies that the total amount of time spent in the infectious period is gamma distributed with mean $\frac{1}{\mu}$ and variance $\frac{1}{n_{I} \mu^{2}}$. As the number of stages increases, the distributions of the latent and 


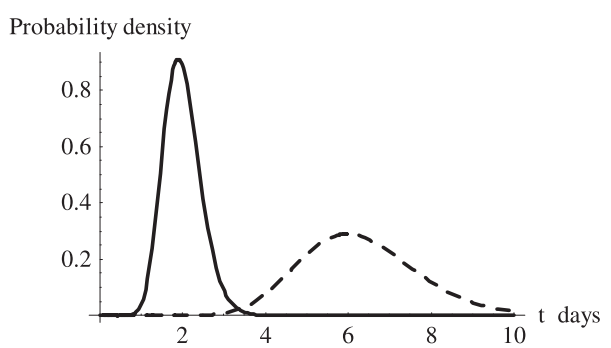

Figure 2. Probability density plot for the gamma distribution of the length of the latent (solid line) and infectious (dashed line) periods in the SEIR model of H7N7 within-flock transmission, in agreement with the transmission experiments [22].

infectious periods become more and more concentrated around the mean values.

Available data from H7N7 experiments with chickens [22] indicate that the latent period is between one and two days, and the infectious period is 6.3 days $(95 \%$ confidence interval (CI): 3.9-8.7). Therefore, $\gamma$ was taken to be $0.5\left(\right.$ day $\left.^{-1}\right)$ (i.e. the mean latent period was two days) and $\mu$ was taken to be $0.159\left(\right.$ day $\left.^{-1}\right)$ (i.e. the mean infectious period was 6.3 days) in agreement with the experiments [22]. The shape parameters $\left(n_{E}\right.$ and $\left.n_{I}\right)$ were set at 20 so that the distributions of the latent and infectious periods correspond to the variation observed between chickens in the experiments. See Figure 2 for the probability density plots for the length of the latent and infectious periods for the default model.

The model is fully specified by five parameters: the mean length and variance of the latent period, the mean length and variance of the infectious period and the transmission rate parameter $\beta$ (dimension: day $\left.^{-1}\right)$. The transmission parameter is a measure for the number of susceptible birds infected by one infectious bird per day. Corresponding with the transmission experiments, we set $\beta 33$ day $^{-1}$ [22]. In our formulation the transmission term was $\beta S(t) I(t) / N(0)$, with $S(t)$ and $I(t)$ denoting the number of susceptible and infectious birds in the population at time $t$, respectively, and $N(0)$ denotes the total number of birds present in the population at the start of the outbreak. This formulation implies that we scale the transmission term with population size for the extrapolation between chicken populations of different sizes. The reason for this is that although chicken populations are of different sizes, e.g. 10 in the transmission experiments and 10000 on a farm, the density is similar since the area on which the chickens are kept is much larger in the latter case $[2,8]$. Thus, in this model the transmission rate parameter is scaled for the initial population size. However, in the model we do not let the transmission depend on the decreasing population size due to mortality during the outbreak, because the decreasing population size will then result in a decreasing density since the area on which the chickens are housed is not decreased [1].

To simulate the outbreaks we used the following discrete time step approach. At any given time $(t)$ the population is characterized by a vector $\left(S(t), E_{1}(t), E_{2}(t), \ldots\right.$, $\left.E_{20}(t), I_{1}(t), I_{2}(t), \ldots, I_{20}(t), R(t)\right)$ describing the number of birds in each separate stage within a class. We denote the number of transitions from the susceptible to the first latent stage by $C_{\left(S \rightarrow E_{1}\right)}$; other transitions are similarly denoted. Given the number of susceptible birds in $\mathrm{S}$ at time $t(S(t))$, the number of birds that is infected in a short time span of length $\Delta t$ is given by:

$$
\begin{aligned}
C_{\left(S \rightarrow E_{1}\right)} \sim^{2} \operatorname{Bin}(S(t), 1- \\
\quad \exp (-\beta I(t) / N(0) \Delta t))
\end{aligned}
$$

Thus, the number of transitions from $\mathrm{S}$ to $\mathrm{E}_{1}$ is binomially distributed with parameter $1-\exp (-\beta I(t) / N(0) \Delta t)$ (the probability of transition of a single bird) and binomial totals $S(t)$. Other transitions are treated in a

\footnotetext{
${ }^{2}$ This mathematical symbol ( ) means "has distribution".
} 
similar manner according to the transition rules in $(1 b-1 e)$.

$$
\begin{aligned}
C_{\left(E_{x} \rightarrow E_{x+11}\right)} & \sim \operatorname{Bin}\left(E_{x}(t), 1\right. \\
& \left.-\exp \left(-\gamma n_{E} \Delta t\right)\right)\left(\text { for } 1 \leq x \leq n_{E}-1\right)
\end{aligned}
$$

$$
\begin{aligned}
C_{\left(E_{n_{E}} \rightarrow I_{1}\right)} \sim \operatorname{Bin}\left(E_{n_{E}}(t), 1\right. \\
\left.-\exp \left(-\gamma n_{E} \Delta t\right)\right)
\end{aligned}
$$

$$
\begin{aligned}
C_{\left(I_{y} \rightarrow I_{y+11}\right)} & \sim \operatorname{Bin}\left(I_{y}(t), 1\right. \\
& \left.\quad-\exp \left(-\mu n_{I} \Delta t\right)\right)\left(\text { for } 1 \leq y \leq n_{I}-1\right)
\end{aligned}
$$

$$
\begin{aligned}
C_{\left(I_{n_{I}} \rightarrow R\right)} \sim \operatorname{Bin}\left(I_{n_{I}}(t)\right. & , 1 \\
& \left.-\exp \left(-\mu n_{I} \Delta t\right)\right)
\end{aligned}
$$

\subsection{Simulation details}

The model simulated within-flock outbreaks, following the transition rules specified in (1). For our default parameter values simulations were started with one latently infected bird in a population of susceptibles totalling 10000 birds. The time-step was set at 0.01 day (i.e. less than $15 \mathrm{~min}$ ). The output of interest was the number of birds that died per day $(\mathrm{R})$; in which one day was defined as lasting from $x .01$ day to $(x+1) .00$ day. For each parameter value combination a thousand iterations of the model were run, which took about $150 \mathrm{~min}$. The model was implemented with MATHEMATICA $5.2^{\circledR}$.

For each iteration of the model, the number of days it took to reach a defined threshold value of dead birds per day (detection rule for determining AI) was listed. The default detection rule was formed by the current Dutch legislation that obliges poultry farmers to notify authorities when mortality among their layers is $0.5 \%$ of the flock or more on each of two consecutive days. Subsequently, the outcomes gave estimates for the time since infection, based on the mode, minimum and maximum of the number of days between infection and detection. Next, the most likely day the virus was introduced into the flock could be back-calculated.

\subsection{Sensitivity analysis}

Sensitivity analyses were performed for flock size, mean length of latent and infectious period and number of virus introductions, by running the model with different values for these parameters. For flock size, values were chosen based on the range of farms in the total field data set; 1000 and 40000 birds. The mean length of the latent period was set at 1.5 and 2.5 days; the latent period does not seem very variable according to the results from transmission experiments [21, 22]. The basic reproduction ratio, $R_{0}$, is an expression for the average number of new cases arising from one infectious chicken in a totally susceptible population [15]. In our model $R_{0}$ is given by the product of the transmission rate parameter $\beta$ and the average infectious period. To maintain internal consistency, $R_{0}$ was kept at the same value, the point estimate resulting from the experiments [22], while varying $\beta$ and the mean length of the infectious period. The $95 \%$ confidence interval limits for the mean infectious period from the transmission experiments were used for the sensitivity analysis: 3.9 days ( $\beta=53.3 /$ day) and 8.7 days ( $\beta=23.9 /$ day) [22]. The number of virus introductions was set at 10 and 100 at time $t=0$.

The outcomes of the default model were also analysed with different detection rules to see how these detection rules influence the detection period: absolute number of dead animals on one day, mean number of dead animals on two consecutive days and cumulative number of dead animals on two consecutive days followed by an absolute number of dead animals on the third day. 
These detection rules aim at a faster start of the increase in mortality, a gradual increase or a recurrent increase.

\subsection{Application of model}

The outcomes of the model were applied on within-flock mortality data from loose-housed layer flocks in the field dataset, which contains data collected from 241 infected and depopulated farms during the Dutch AI epidemic in 2003. There were 92 loose-housed layer flocks with at least two consecutive daily mortality data points. The flock size ranged from 480 to 37375 chickens, with a median of 6719 .

We applied the current Dutch monitoring threshold for notification, which is at least $0.5 \%$ within-flock mortality on each of two consecutive days for layer flocks [14], on these loose-housed layer flocks to illustrate the use of the model. At the time of the epidemic, this notification threshold was not in use. The results will be presented according to the backcalculated interval between theoretical notification and depopulation.

\section{RESULTS}

\subsection{Model}

The default model output is the number of susceptible (S), latently infected (E), infectious (I) and dead (R) chickens per day after a single virus introduction into a 10000 chicken flock (Fig. 3). Note that the main difference between the iterations was the time of epidemic onset, depicted in the E plot in Figure 3. A noticeable rise $(>0.5 \%)$ in the number of dead chickens was visible from day ten on $(\mathrm{R}$ plot in Fig. 3), and most of the susceptible chickens became infected after nine to twelve days (> 95\%; I plot in Fig. 3). The sharp peak in E compared to I was in agreement with the small variation in the latency
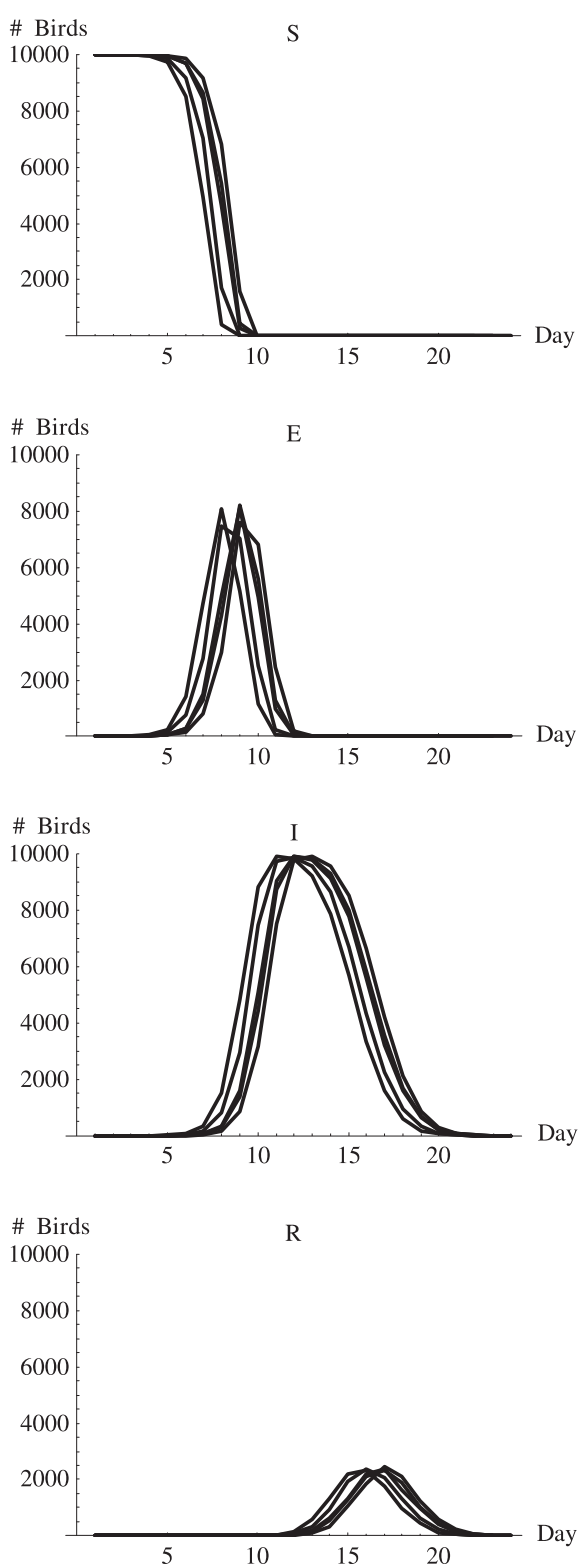

Figure 3. Examples of the model output for flocks of 10000 chickens; five iterations. Shown is the number present per day of susceptible chickens (S), the number of latently infected chickens (E), the number of infectious chickens (I) and the number of dead chickens (R) after the introduction of one H7N7 infected chicken into the flock at day one. 
Table I. Estimated day (mode (minimum-maximum)) of single introduction of the H7N7 AI virus into a layer flock in terms of the number of days before detection, according to various mortality threshold values (X; number of dead birds) and flock sizes. The first column gives the number of chickens present in the flock, the second column gives the threshold number and percentage for detection, and the third, fourth, fifth and sixth column give the different detection rules for which the second column forms the basis.

\begin{tabular}{lcccccc}
\hline Flock size & \multicolumn{2}{c}{ Mortality threshold } & $\begin{array}{c}\text { X Dead } \\
\text { per day }\end{array}$ & $\begin{array}{c}\text { X Dead on each } \\
\text { of } 2 \text { consecutive } \\
\text { days }\end{array}$ & $\begin{array}{c}\text { X Mean dead } \\
\text { on 2 days }\end{array}$ & $\begin{array}{c}\text { X Cumulative dead } \\
\text { on 2 consecutive days } \\
\text { + X dead on 3rd day }\end{array}$ \\
\hline 10000 & 1 & 0.01 & $9(5-11)$ & $10(7-12)$ & $9(7-11)$ & $10(7-12)$ \\
10000 & 5 & 0.05 & $10(8-12)$ & $11(9-13)$ & $10(9-12)$ & $11(9-13)$ \\
10000 & 15 & 0.15 & $11(9-12)$ & $12(10-13)$ & $11(9-13)$ & $11(10-13)$ \\
10000 & 50 & 0.5 & $11(10-14)$ & $12(11-15)^{\mathrm{a}}$ & $12(10-14)$ & $12(11-14)$ \\
10000 & 500 & 5 & $13(12-15)$ & $14(13-16)$ & $13(12-15)$ & $14(13-16)$ \\
\hline 100 & 15 & 15 & $11(10-13)$ & $12(11-15)$ & $12(10-14)$ & $12(10-14)$ \\
4000 & 15 & 0.38 & $11(9-13)$ & $12(10-14)$ & $11(9-13)$ & $11(10-13)$ \\
40000 & 15 & 0.04 & $11(9-12)$ & $12(10-13)$ & $11(10-13)$ & $11(10-13)$ \\
\hline
\end{tabular}

${ }^{a}$ Default model outcome: current Dutch monitoring rule for notification $(\geqslant 0.5 \%$ on each of two consecutive days).

period in comparison with the infectious period.

The estimated day of single introduction of the virus into a flock according to the model is shown in Table I. For the default model with the default detection rule (50 dead animals or more on each of two consecutive days) we found that the virus was introduced most likely $12(11-15)$ days before detection.

\subsection{Sensitivity analysis}

The results for the sensitivity analyses are given in Tables I and II.

Decreasing the latent period with half a day decreases the detection period with one day, whereas increasing the latent period with half a day leads to a two day longer detection period. Note that a longer latent period leads to a wider minimum to maximum range. Decreasing or increasing the infectious period seems to shift the detection period as a whole: the range stays four days. Increasing the number of virus introductions on a single day (at time $t=0$ ) reduces the detection period, and seems to reduce the range of time since the virus might have been introduced. Flock size has little influence on the estimated day of virus introduction. When the current Dutch monitoring rule is applied to a flock of a thousand chickens or of 40000 chickens the most likely day of introduction only changes one day from the default model outcome. In Table I it can be seen that changing the detection rule also has little effect on the detection period.

\subsection{Application of model}

After applying the results of the default model on our field dataset according to the current Dutch notification legislation, we found that out of the 92 loose-housed layer flocks 71 did not reach the threshold value. During the later part of the epidemic, the notification threshold was rarely reached before depopulation. 
Table II. Sensitivity analysis on the estimated day (mode (minimum-maximum)) of introduction of the H7N7 AI virus into a flock in terms of the number of days before detection, according to the monitoring threshold value in the Netherlands (i.e. $\geq 0.5 \%$ mortality on each of two consecutive days). The first column gives the model adaptation, the following columns give the length of the latent and infectious period, number of virus introductions and flock size, and the last column gives the estimated day since virus introduction: the mode is given in dark grey and the range is given in light grey. $\times$ and - denote the mode and range of the default model, respectively.

\begin{tabular}{|c|c|c|c|c|c|c|c|c|c|c|c|c|c|}
\hline \multirow{2}{*}{ Model } & \multirow{2}{*}{$\begin{array}{l}\text { Length } \\
\left(T_{E}\right) \text { (days) }\end{array}$} & \multirow{2}{*}{$\begin{array}{l}\text { Length } \\
\left(\mathrm{T}_{\mathrm{I}}\right) \text { (days) }\end{array}$} & \multirow{2}{*}{$\begin{array}{l}\# \\
\text { Introductions }\end{array}$} & \multirow{2}{*}{$\begin{array}{l}\text { Flock } \\
\text { size }\end{array}$} & \multicolumn{9}{|c|}{ Day since introduction } \\
\hline & & & & & 8 & 9 & 10 & 11 & 12 & 13 & 14 & 15 & 16 \\
\hline Default & 2 & 6.3 & 1 & 10000 & & & & - & $\mathrm{X}$ & - & - & - & \\
\hline \multirow[t]{2}{*}{ Length $\mathrm{T}_{\mathrm{E}}$} & 1.5 & 6.3 & 1 & 10000 & & & & - & $\mathrm{X}$ & - & - & - & \\
\hline & 2.5 & 6.3 & 1 & 10000 & & & & - & $\mathrm{X}$ & - & - & - & \\
\hline \multirow[t]{2}{*}{ Length $T_{I}$} & 2 & $3.9^{\mathrm{a}}$ & 1 & 10000 & & & & - & $\mathrm{X}$ & - & - & - & \\
\hline & 2 & $8.7^{\mathrm{b}}$ & 1 & 10000 & & & & - & $X$ & - & - & - & \\
\hline \multirow[t]{2}{*}{ \# Introductions } & 2 & 6.3 & 10 & 10000 & & & & - & $\mathrm{X}$ & - & - & - & \\
\hline & 2 & 6.3 & 100 & 10000 & & & & - & $\mathrm{X}$ & - & - & - & \\
\hline \multirow[t]{2}{*}{ Flock size } & 2 & 6.3 & 1 & 1000 & & & & - & $\mathrm{X}$ & - & - & - & \\
\hline & 2 & 6.3 & 1 & 40000 & & & & - & $\mathrm{X}$ & - & - & - & \\
\hline
\end{tabular}

${ }^{\text {a }}$ To maintain the same value for $R_{0}$ the $\beta$ for this simulation is set at 53.3 and for ${ }^{\mathrm{b}} \beta$ is set at 23.9 (default value: 33 ).

In the 21 flocks that did reach the mortality threshold, four flocks were depopulated on the day the monitoring rule theoretically would have caused notification (see Tab. III). The other seventeen flocks were depopulated between one and nine days after theoretical notification. These latter flocks were among the first flocks detected during the epidemic. Table III shows that the flocks that were depopulated after the threshold would have been reached were longer infections than in our simulation output.

See Figure 4 for the comparison of within-flock mortality data of a farm that did reach the monitoring threshold before depopulation (Farm A) and a farm that did not reach this threshold (Farm B) with results of the model (R).

\section{DISCUSSION}

In this paper a new tool was developed for back-calculating the day of H7N7
HPAI virus introduction into a flock based on H7N7 related mortality data of this flock. The within-flock mortality was easily obtainable, since poultry keepers routinely record this. Therefore, the model can provide a quick overview of when the flock was most likely infectious to other flocks and during which period tracing should take place.

The model was robust for flock size and detection rule: there was little variation in the outcomes for different flock sizes or detection rules (see Tab. I). This is likely due to the relatively large susceptible flock size, as compared to one infectious bird. Another reason will be the fact that we measured directly at the beginning of the outbreak, when the number of dead birds was increasing exponentially because of the large number of susceptible birds. The model shows only slightly different variation when the length of the latent and infectious periods were changed, or when multiple introductions were modeled (see Tab. II). It is important that the values for 
Table III. Application of the 10000 flock size model results on field data. Theoretical notification was calculated according to the current Dutch legislation for notification $(\geq 50$ dead animals on each of two consecutive days). The first column gives information characterizing the number of loosehoused layer flocks mentioned in the second column. The third column gives the back-calculated length of the period between virus introduction and depopulation, given in (mode (minimummaximum)) days.

\begin{tabular}{lcc}
\hline Flocks in field dataset & $\begin{array}{c}\text { \# Flocks } \\
(n=92)\end{array}$ & $\begin{array}{c}\text { Back-calculated period between } \\
\text { virus introduction and depopulation } \\
\text { (mode (minimum-maximum) days) }\end{array}$ \\
\hline $\begin{array}{l}\text { Depopulated before threshold for theoretical notification } \\
\text { Depopulated within 0 days after theoretical notification }\end{array}$ & 71 & $12(11-15)$ \\
Depopulated within 1 days after theoretical notification & 9 & $13(12-16)$ \\
Depopulated within 2 days after theoretical notification & 5 & $14(13-17)$ \\
Depopulated within 6 days after theoretical notification & 1 & $17(16-20)$ (Fourth detected case) \\
Depopulated within 8 days after theoretical notification & 1 & 20 (19-23) (First detected case) \\
Depopulated within 9 days after theoretical notification & 1 & $21(20-24)$ (Second detected case) \\
\hline
\end{tabular}

${ }^{a}$ Default model outcome.

these parameters be well defined, preferably with high precision, which will never be the case in small-scale transmission experiments.

The results also show that, according to the model, roughly all chickens in a flock are infectious before the number of dead chickens begins to noticeably increase. This means that by the time a poultry keeper notices an unusually high number of dead chickens, the H7N7 virus could already have been spreading between flocks for almost two weeks. This was also found by Stegeman et al. (2004) [20] who determined the infectious period to be 13.8 (95\% CI: 9.9-17.6) days for flocks suspected of infection with AI on the first day of detection of the H7N7 epidemic in the Netherlands in 2003. After the epidemic was detected, the infectious period was shown to decrease to $7.3(95 \% \mathrm{CI}$ : 3.4-11.1) days, due to control measures. The results of the model show that infectious chickens can be present in the flock from day one until day 26 , indicating that this is the period during which a flock can be infectious to other flocks.
Two previous models for determining the day of virus introduction into a herd were designed by Stegeman et al. (2004) [19] and Laevens et al. (1998) [11]. These models for Classical Swine Fever virus introduction into a herd of pigs, were based on serological results of either a sample of (13-54\% [19]) or all pigs in a herd [11]. They relied upon knowing the exact day of introduction for some herds, based on the contact that caused the infection. In our case, neither the contact nor the exact day of introduction was known, nor was extensive virus isolation performed to estimate within-flock prevalence. However, high within-flock mortality can be a good indication of HPAI infection of a flock, and these data were retrospectively collected after diagnosis of the flock. Therefore, during an HPAI epidemic, all poultry farmers should be asked to maintain daily mortality records, at least for the duration of the epidemic.

A careful examination of assumptions underlying a model is always necessary [7]. The model uses a discrete time step approach to simulate a continuous 

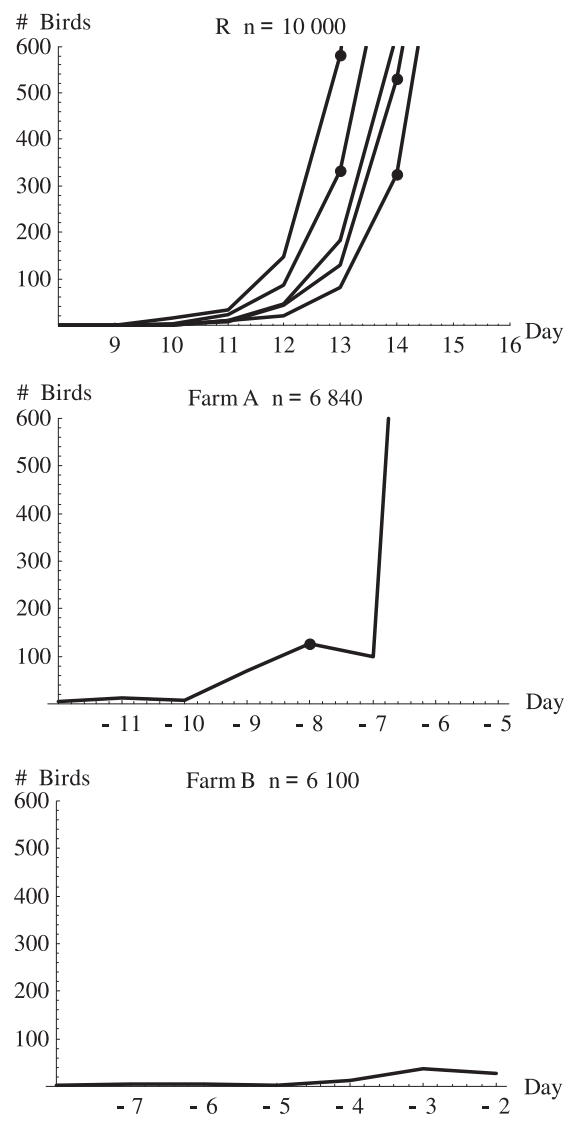

Figure 4. R output of the model (five iterations shown) in detail (R) compared to field data: within-flock mortality of a farm which reached the current monitoring threshold before depopulation (Farm A) and a farm which did not reach the threshold before depopulation (Farm B). The dots represent the day the theoretical monitoring threshold would have been reached and day zero represents the day of depopulation. For $\mathrm{R}$ the $\mathrm{x}$-axis shows the number of days since virus introduction (= day one). In all graphs the $y$-axis represents the number of dead animals.

process. Internal validation showed that the model yields the same results as a continuous approach would have (results are not shown).

The decision to include a latent period in the model was based on the transmis- sion experiments. In the transmission experiments with $\mathrm{H} 7 \mathrm{~N} 7$, a latent period of two days was used [22]. This latent period was based on previous transmission experiments, in which a model based on a latent period of one to two days fit the data better than a latent period of one day [21]. Also, we decided that we could not ignore a latent period which is a third of the infectious period.

Our model used parameter values derived from two transmission experiments, each with five infectious and five susceptible chickens [22]. This number is common for transmission experiments, but we do not know how these results relate to field conditions where tens of thousands of chickens are housed together. We decided to use these parameter values nonetheless, because values from field conditions are still unknown, and the transmission experiment results were reasonably defined for the length of the latent and infectious period. Moreover, one of the goals of our model was to extrapolate results from transmission experiments to field conditions.

Another assumption made in this model is that all $\mathrm{R}$ chickens were dead. However, in the transmission experiments 3 out of 10 susceptible chickens survived a H7N7 contact infection [22], meaning that some $\mathrm{R}$ chickens in the experiments recovered. Given that the dead chickens counted in field data may only form a part of the $\mathrm{R}$ chickens in the model, the model may overestimate the number of dead chickens. This may lead to an underestimation of the time since introduction. In addition, the animals that died in the experiments had a shorter infectious period than did the surviving animals, indicating the need for two different I populations. However, because of scarcity of data, we chose to model all I chickens similarly.

In contrast to the default model with one latently infected chicken at the start of the outbreak, multiple introductions lead 
to a quicker increase in the number of dead chickens. Therefore, multiple introductions lead to a shorter period between infection and detection, although, according to the model, the difference is only between one and three days. Since it is seldom known for AI outbreaks how many introductions have taken place, and the difference is small, we think it better to opt for being on the safe side and use one introduction in the model. This caution is especially appropriate given that the main use for this model is to support control measures, by defining the period for tracing.

The model excluded non-AI related mortality, since no reliable normal daily mortality default values could be obtained. However, in the light of the chosen mortality thresholds, only during an outbreak of some other pathogen the Dutch monitoring rule would be triggered. Such 'false positives' (i.e. false AI detections) are not considered a problem during an H7N7 epidemic, but might cause a problem when the H7N7 virus is not present in the country. This is a common specificity problem of any detection rule based on 'syndrome monitoring'.

When used for control purposes, it has to be kept in mind that this model is based on assumptions from transmission experiments. We do not recommend that tracing only needs to focus on the period before notification as estimated from this model. The current Dutch regulations are that backward-tracing should be done for at least three weeks prior to the diagnosis of AI in the flock; and this period might be extended depending on the assumed moment of infection based on mortality and symptoms ${ }^{3}$. This seems long but safe compared to our model results, which give a period of 12 (11-15) days between H7N7

\footnotetext{
${ }^{3}$ VWA, Traceren, Algemene informatie, in: Draaiboek AI [on line] (2001) http://www.rvv.agro. nl/mavim/draaiboeken/AI_2001/default.htm [consulted 7 July 2006].
}

virus introduction and suspicion according to the monitoring threshold, as seen in Table I. If resources are scarce, as is commonly the case in the early epidemic phase, two weeks of tracing would cover the highest risk period for loose housed laying hen flocks and save resources.

After applying the current Dutch legislation for notification to the field dataset, it was shown that the majority of the flocks in this dataset never reached this within-flock mortality threshold. This indicates that after the first two weeks of the epidemic, flocks were detected before their withinflock mortality theoretically would have caused notification. This may be because poultry keepers were paying more attention to the health of their flocks because of the ongoing epidemic, and therefore already notified authorities when they had a little excess mortality, thus creating a test system with high sensitivity. According to our model results, the flocks that did reach the mortality threshold might have been spreading the virus to other flocks for 11-24 days before they were depopulated (see Tab. III). If the current Dutch monitoring threshold had been in place, the first outbreaks would have been detected earlier.

In conclusion, this type of model can be a useful tool to back-calculate the day of HPAI H7N7 virus introduction and thus support control measures, but needs to be based on sound data on pathogen transmission. Although it was developed using H7N7 HPAI virus as an example, the tool can also be modified for other viruses that follow a similar SEIR pattern and result in high mortality with the possibility to record all mortality from the whole flock or herd. The population should follow homogeneous mixing patterns, therefore the model might not be useful for e.g. caged animals. We assume that in battery caged flocks the transmission of H7N7 HPAI will be slower than in loose housed flocks because of spatial separation of the cages. 
Savill et al. (2006) [16] indeed found a within-flock $R_{0} \approx 66$ for unvaccinated floor-reared birds and $R_{0} \approx 25$ for caged systems with 8 birds per cage for their HPAI H5N1 model.

To use this model, it is important to collect daily mortality data and maintain these records at least for the duration of the epidemic.

\section{ACKNOWLEDGEMENTS}

We would like to thank Don Klinkenberg, Linda McPhee and two anonymous reviewers for critical reading of the manuscript and providing us with valuable recommendations. This work was supported by EU Grant SSPE-CT2004-513737 (HEALTHY POULTRY).

\section{REFERENCES}

[1] Begon M., Bennett M., Bowers R.G., French N.P., Hazel S.M., Turner J., A clarification of transmission terms in host-microparasite models: numbers, densities and areas, Epidemiol. Infect. (2002) 129:147-153.

[2] Bouma A., De Jong M.C.M., Kimman T.G., Transmission of pseudorabies virus within pig populations is independent of the size of the population, Prev. Vet. Med. (1995) 23:163-172.

[3] Bowes V.A., Ritchie S.J., Byrne S., Sojonky K., Bidulka J.J., Robinson J.H., Virus Characterization, Clinical Presentation, and Pathology Associated with H7N3 Avian Influenza in British Columbia Broiler Breeder Chickens in 2004, Avian Dis. (2004) 48:928-934.

[4] Capua I., Marangon S., Selli L., Alexander D.J., Swayne D.E., Dalla Pozza M., Parenti E., Cancellotti F.M., Outbreaks of highly pathogenic avian influenza (H5N2) in Italy during October 1997 to January 1998, Avian Pathol. (1999) 28:455-460.

[5] Capua I., Mutinelli F., Marangon S., Alexander D.J., H7N1 avian influenza in Italy (1999 to 2000) in intensively reared chickens and turkeys, Avian Pathol. (2000) 29:537-543.

[6] Cox D.R., Miller H.D., Some miscellaneous topics, in: The theory of stochastic processes,
Chapman and Hall Ltd, London, 1967, pp. 186-189.

[7] De Jong M.C.M., Mathematical modelling in veterinary epidemiology: why model building is important, Prev. Vet. Med. (1995) 25:183-193.

[8] De Jong M.C.M., Diekmann O., Heesterbeek J.A., How does transmission of infection depend on population size? in: Mollison D. (Ed.), Epidemic models: Their structure and relation to data, Press Syndicate of the University of Cambridge, Cambridge, 1995, pp. 484-494.

[9] Elbers A.R.W., Moser H., Ekker H.M., Crauwels P.A.A., Stegeman J.A., Smak J.A., Pluimers F.H., Tracing systems used during the epidemic of classical swine fever in the Netherlands, 1997-1998, Rev. Sci. Tech. Off. Int. Epizoot. (2001) 20:614-629.

[10] Elbers A.R.W., Fabri T.H.F., De Vries T.S., De Wit J.J., Pijpers A., Koch G., The highly pathogenic avian influenza A (H7N7) virus epidemic in The Netherlands in 2003-lessons learned from the first five outbreaks, Avian Dis. (2004) 48:691-705.

[11] Laevens H., Deluyker H., Koenen F., Van Caenegem G., Vermeersch J.P., De Kruif A., An experimental infection with a classical swine fever virus in weaner pigs: II. The use of serological data to estimate the day of virus introduction in natural outbreaks, Vet. Q. (1998) 20:46-49.

[12] Lloyd A.L., Destabilization of epidemic models with the inclusion of realistic distributions of infectious periods, Proc. R. Soc. Lond. B Biol. Sci. (2001) 268:985-993.

[13] Lloyd A.L., Realistic distributions of infectious periods in epidemic models: changing patterns of persistence and dynamics, Theor. Popul. Biol. (2001) 60:59-71.

[14] Ministry of Agriculture, N.a.F.Q., Wijziging Regeling ter wering van Aviaire Influenza II en de Regeling Preventie, bestrijding en monitoring van besmettelijke dierziekten en zoönosen en TSE's, Staatscourant (2005) 204:12.

[15] Noordhuizen J.P.T.M., Frankena K., Thrusfield M.V., Graat E.A.M., Application of quantitative methods in veterinary epidemiology, Wageningen Pers., Wageningen, 2001.

[16] Savill N.J., St. Rose S.G., Keeling M.J., Woolhouse M.E.J., Silent spread of H5N1 in vaccinated poultry, Nature (2006) 442: 757.

[17] Shortridge K.F., Zhou N.N., Guan Y., Gao P., Ito T., Kawaoka Y., Kodihalli S., Krauss 
S., Markwell D., Murti K.G., Norwood M., Senne D., Sims L., Takada A., Webster R.G., Characterization of avian H5N1 influenza viruses from poultry in Hong Kong, Virology (1998) 252:331-342.

[18] Smith G.J.D., Naipospos T.S.P., Nguyen T.D., de Jong M.D., Vijaykrishna D., Usman T.B., Hassan S.S., Nguyen T.V., Dao T.V., Bui N.A., Evolution and adaptation of H5N1 influenza virus in avian and human hosts in Indonesia and Vietnam, Virology (2006) 350:258-268.

[19] Stegeman A.J., Elbers A.R.W., Bouma A., De Smit H., De Jong M.C.M., Transmission of classical swine fever virus within herds during the 1997-1998 epidemic in The Netherlands, Prev. Vet. Med. (1999) 42:201-218.
[20] Stegeman A.J., Bouma A., Elbers A.R.W., De Jong M.C.M., Nodelijk G., De Klerk F., Koch G., Van Boven M., Avian influenza A virus (H7N7) epidemic in The Netherlands in 2003: course of the epidemic and effectiveness of control measures, J. Infect. Dis. (2004) 190:2088-2095.

[21] Van der Goot J.A., De Jong M.C.M., Koch G., Van Boven M., Comparison of the transmission characteristics of low and high pathogenicity avian influenza A virus (H5N2), Epidemiol. Infect. (2003) 131:1003-1013.

[22] Van der Goot J.A., Koch G., De Jong M.C.M., Van Boven M., Quantification of the effect of vaccination on transmission of avian influenza (H7N7) in chickens, Proc. Natl. Acad. Sci. USA (2005) 102:18141-18146. 